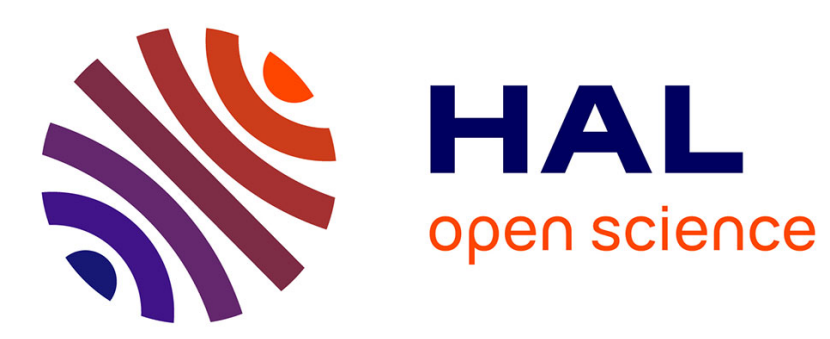

\title{
A novel approach to obviousness: An algorithm for identifying prior art concerning 3-D printing materials Joshua Pearce
}

\section{To cite this version:}

Joshua Pearce. A novel approach to obviousness: An algorithm for identifying prior art concerning 3-D printing materials. World Patent Information, 2015, 42, pp.13-18. 10.1016/j.wpi.2015.07.003 . hal-02111333

\section{HAL Id: hal-02111333 \\ https://hal.science/hal-02111333}

Submitted on 26 Apr 2019

HAL is a multi-disciplinary open access archive for the deposit and dissemination of scientific research documents, whether they are published or not. The documents may come from teaching and research institutions in France or abroad, or from public or private research centers.
L'archive ouverte pluridisciplinaire HAL, est destinée au dépôt et à la diffusion de documents scientifiques de niveau recherche, publiés ou non, émanant des établissements d'enseignement et de recherche français ou étrangers, des laboratoires publics ou privés. 
Pre-print: Joshua M. Pearce. A novel approach to obviousness: An algorithm for identifying prior art concerning 3-D printing material. World Patent Information 42, 13-18 (2015). doi:10.1016/j.wpi.2015.07.003

\title{
A Novel Approach to Obviousness: An Algorithm for Identifying Prior Art Concerning 3-D Printing Materials Joshua M. Pearce
}

Department of Materials Science \& Engineering and Department of Electrical \& Computer Engineering, Michigan Technological University 601 M\&M Building, 1400 Townsend Drive, Houghton, MI 49931-1295 pearce@mtu.edu

Keywords: 3-D printing; additive manufacturing; materials; 3-D printer filament; 3-D ink; intellectual property; prior art; intellectual monopoly; public domain; open source; open source materials; libre

\begin{abstract}
With the development and commercialization of the recyclebot (plastic extruders that fabricate 3-D printing filament from recycled or virgin materials) and various syringe pump designs for selfreplicating rapid prototypers (RepRaps), the material selection available for consumers who produce products using 3-D printer operators is expanding rapidly. This paper provides an open-source algorithm for identifying prior art for 3-D printing materials. Specifically this paper provides a new approach for determining obviousness in this technology area. The potential ramifications on both innovation and patent law in the 3-D printing technological space are discussed.
\end{abstract}

Keywords: 3-D printing; additive manufacturing; materials; 3-D printer filament; 3-D ink; intellectual property; prior art; intellectual monopoly; public domain; open source; open source materials; libre

\section{Introduction}

3-D printing has been growing aggressively and authors with as diverse views as Jeremy Rifkin $\left.{ }^{1}\right]$ and the Economist $\left.{ }^{[2}\right]$ have predictions that agree that additive manufacturing (AM) technology will provide a new industrial revolution, fundamentally changing the way products are made [ $\left.{ }^{3}\right]$. The relatively sudden widespread attention is largely due to the development of the open-source selfreplicating rapid prototyper (or RepRap) $[4,5]$ and the concomitant tidal wave of innovation that has resulted in radically reduced costs of 3-D printers, rapid prototyping and low-volume production $\left[{ }^{6},{ }^{7}\right]$. Although RepRaps and their commercial derivatives (now available from hundreds of small companies) can print in a wide selection of materials, the vast majority of 3-D printers today use some form of fused filament fabrication (FFF) [ $\left.{ }^{8}\right]$. Currently, most systems are limited to polylactic acid (PLA) and acrylonitrile butadiene styrene (ABS), with a retail cost of generic filament between US\$35$50 / \mathrm{kg}$. Although proprietary filament is considerably more expensive (starting at US $\$ 70 / \mathrm{kg}$ and going up to over US\$200/kg), RepRap printed products from generic retail ABS and PLA materials have been shown to be as strong as proprietary 3-D prints [ $\left.{ }^{9}\right]$. Even with the high cost of commercial plastic filament slowing deployment, there has still been a rapid growth in the sector with personal 3-D printer sales increasing by $35,000 \%$ from 2007 to $2012\left[{ }^{10}\right]$.

The recent development of the open-source recyclebot $\left[{ }^{11}\right]$ (a waste plastic extruder capable of producing filament at US\$0.10/kg from electricity costs from post-consumer plastic containers) $\left[{ }^{12}\right]$ is 
Pre-print: Joshua M. Pearce. A novel approach to obviousness: An algorithm for identifying prior art concerning 3-D printing material. World Patent Information 42, 13-18 (2015). doi:10.1016/j.wpi.2015.07.003

likely to further accelerate 3-D printing deployment by largely eliminating the cost barrier of feedstock even for the world's poorest citizens $\left[{ }^{13}\right]$. In addition, it is likely to increase the number of 3-D printing materials as soon as thousands of prosumers (a portmanteau of producing consumer, which make their own products) will be able to experiment in producing their own 3-D printer materials using either a home-built recyclebot ${ }^{\left[{ }^{14}\right]}$ (e.g. the Lyman Filament Extruder [ $\left.{ }^{15}\right]$ ) or simply purchase any of the growing number of commercial variants (e.g. FilaFab $\left[{ }^{16}\right]$, Filabot $\left[{ }^{17}\right]$, FilaStruder $\left[{ }^{18}\right]$, etc.). The prosumer community has even developed a sophisticated recycling code system to allow for more 3-D printing materials to be utilized [ $\left.{ }^{19}\right]$. Open-source 3-D printer material development to date has largely relied on experimental trial and error. Although the combinatorial experimental brute force made possible with hundreds of virtual collaborators following the open source model of development is probable to yield results, it is an inefficient use of resources. A more efficient mechanism to help accelerate development of technology is to consider innovation algorithms. Such algorithms, like the TRIZ algorithm for inventive problem solving, for example has proven successful in the past in a large number of applications $\left[{ }^{20},{ }^{21},{ }^{22},{ }^{23}\right]$. For example, the TRIZ algorithm was applied to recyclebot technology to produce a low-cost largely 3-D printable version of the recyclebot in Germany $\left[{ }^{24}\right]$.

In order to assist the development of materials for low-cost open-source 3-D printers, this paper provides an open-source algorithm for generating prior art for 3-D printing materials to release into the public domain. The use of the algorithm is explained to systematically generate a wide range of 3-D printing materials for use commercially or by any 3-D printer and recyclebot operator. Two case studies are then provided for utilizing the algorithm. First, the algorithm is used to narrow the search for 3-D printable materials with specific properties and second to probe the obviousness requirements of patents. This could be used as an intellectual monopoly prophylaxis against overly broad patent applications based on vague, formulaic, generic and combinatorial claims filed by either practicing or non-practicing entities. The potential ramifications on both innovation and intellectual property in the 3 -D printing area is discussed and conclusions are drawn.

\section{Materials and Methods}

\subsection{Variables and definitions:}

$\mathrm{N}=$ the total number of natural chemicals and compounds including the entire set of elements in the periodic table

$\mathrm{M}=$ the total number of known man-made chemicals. This includes, but is not limited to, the entire CAS Registry $\left.{ }^{[25}\right]$, which is the most authoritative collection of disclosed chemical substance information, containing more than 100 million unique organic and inorganic chemical substances and more than 66 million sequences. (It should be noted that the algorithm should be updated with the CAS Registry, which has expanded by more than $15 \%$ from the initial draft of this paper. $\mathrm{F}=\mathrm{a}$ functional agent that represents any chemical species that provides some form of beneficial property of the 3-D printing material or any combination of functional agents to provide a combination of functions (e.g. $F_{1}, F_{2}$, etc.). For example, functional agents may include (but are not limited to) species to improve rheological properties, melting temperature, setting time, hydrodynamics (e.g. hydrophobicity, hydrophillicity, etc.), electromagnetic properties (e.g. phosphorescence, color, light transmission, reflection and refraction etc.), chemical properties (e.g. reactivity, smell, catalytic 
Pre-print: Joshua M. Pearce. A novel approach to obviousness: An algorithm for identifying prior art concerning 3-D printing material. World Patent Information 42, 13-18 (2015). doi:10.1016/j.wpi.2015.07.003

activity, etc.), acoustical properties, atomic properties, mechanical properties (e.g. strength, flexibility, stiffness, fracture toughness, etc.), thermal properties (e.g. thermal conductivity, thermoluminescence, etc.), magnetic properties, electrical properties, environmental properties, manufacturing properties (e.g. printability, print speed, ability to form complex geometries without support, bed adhesion, etc.) or radiological properties, etc.

$@=$ All of the preceding materials and

$\&=$ All combinations of all possible mol fractions of the above (e.g. [1] chemicals $a+b, a+c, a+b+c$, etc. until all combinations have been reached over the set up to $\mathrm{N}+\mathrm{M}$ and [2] all fractions so that compound $\left[\mathrm{a}_{\mathrm{x}}\right]\left[\mathrm{b}_{1-\mathrm{x}}\right]$ would be stepped through from $\mathrm{x}=0$ to 1 under all percentages)

\subsection{Materials capable of being used as 3-D printed feedstock include:}

1. Known natural chemicals and compounds including all organic and inorganic substances (these are not patentable).

2. @ \& from 1 to $\mathrm{N}$

3. @ known man-made chemicals, compounds, and metamaterials $\left[{ }^{26},{ }^{27}\right]$ including all organic and inorganic substances

4. @ \& from 1 to $M$

5. @ \& from 1 to NM

6. @ \& where 1 to NM acts as functional agents

7. @ \& where any natural or manmade material is controlled for size from 1 Angstrom to $1 \mathrm{~m}$ in dimension (This is necessary to account for any size related physical or chemical property change as is well established these are tunable at the nanoscale for a wide range of materials[ $\left.{ }^{28}\right]$.)

8. @ \& any arrangement of the combinations (e.g. superlattices, metamaterials, core in shell quantum dots, etc.)

9. @ \& where a nanoscale collection of atoms (e.g. nanocrystal, quantum dot, nanotube, nanocolum, etc.) is used as a functional agent or filler

10. @ \& where the shape of the collection of atoms is altered to adjust properties (thus all geometric shapes, and all known complex shapes capable of being generated by a mathematical algorithm (e.g. fractals)

11. @ \& where the surfaces (both internal voids or external surfaces) are adjusted (e.g. roughening) to adjust properties.

12. @ \& at any temperature from $0 \mathrm{~K}$ to infinity (or any sequence or combination of temperature)

13. @ \& at any pressure from 0 bar to infinity (or any sequence or combination of pressure)

14. @ \& printed in any environmental medium [NM] (meaning that some 3-D printing materials may need to be used under vacuum, under water, in an oil bath, etc.)

15. @ \& printed with the assistance of electromagnetic radiation of any wavelength.

16. @ \& printed with the assistance of any solvent from $\mathrm{N}$ or $\mathrm{M}$ or combination of the above.

17. @ \& for any physical orientation of the chemical species.

18. @ \& for any $\mathrm{N}$ or $\mathrm{M}$ or combination that acts as a catalyst during the printing process.

19. @ \& for any field catalyzed reaction (e.g. magnetic).

20. @ any order of the above. 
Pre-print: Joshua M. Pearce. A novel approach to obviousness: An algorithm for identifying prior art concerning 3-D printing material. World Patent Information 42, 13-18 (2015). doi:10.1016/j.wpi.2015.07.003

\section{How to use the Algorithm:}

Two case studies are evaluated to demonstrate the use of the algorithm:

\subsection{Case Study 1}

Case Study 1 shows how to narrow the search for 3-D printable materials with specific properties. This is particularly important for enterprises investigating new public domain 3-D printing materials for commercialization as well as prosumers needing a 3-D material not yet available on the market.

Consider the following materials engineering design problem: structures of historical significance are often conserved to maintain our cultural heritage $\left[{ }^{29}\right]$. Unfortunately, historical buildings relied on fossil-fuel-based energy systems and for old structures positioned off of the grid, the continued use of these fuel systems represents an unacceptable environmental and economic burden [ ${ }^{30}$, ${ }^{31},{ }^{32},{ }^{33}$. Thus, a challenging materials design problem exists created by the need to provide off-grid power with a low ecological footprint $\left.{ }^{34}\right]$ for a historically protected structure. A material must be designed that has solar photovoltaic (PV) properties to provide sustainable electric power $\left.{ }^{35}\right]$ capable of being deposited on arbitrary complex geometries while still able to be colored over a wide spectrum of colors and surface finishes to conserve historical aesthetics. Obviously this problem could be solved with a 3-D printable photovoltaic material, capable of adjusting color and surface finish, while also conformally covering non-uniform historical building facades. Unfortunately, the commercialized photovoltaic materials are not amenable to 3-D printing as the dominant crystalline silicon technology are grown as single crystal ingots sliced into wafers and thin film PV materials are normally produced under vacuum conditions on large sheets of flat glass [ $\left.{ }^{36}\right]$. To help guide this materials selection problem, the algorithm produces several suggestions of materials fitting into a specific class such as a material from the selection of $\mathrm{N}$ and $\mathrm{M}$ that act as a PV functional agent (Term 6) and could take advantage of Term 7, where the material is controlled for size in the nanoscale range so as to tune the optical absorption of the spectra to allow for color matching to the historic materials. Term 9, recommends a nanoscale collection of atoms such as quantum dot could be used as a functional agent or filler inside a printable ink. For example, colloidal quantum dots can be used to fabricate solar cells $\left[{ }^{37}\right]$ with inkjet printing and it is not hard to imagine connecting an inkjet head to any number of 3-D printers or 3-D stage printers to meet the requirements [ $\left.{ }^{38}\right]$. The algorithm provides many more options such as adding a thin metal-based plasmonic absorber to the top of the cell tuned to adjust the appearance of the cell rather than provide broad band absorption, as is done normally to maximize performance following suggestions from Terms 3, 7 and $9\left[{ }^{39}\right]$. As of the writing of this article, no one has published such PV 3-D printing, but it is clearly a predictably emergent technology and the algorithm can be used to find many other suitable materials for such an application.

\subsection{Case Study 2}

A second Case Study is using the algorithm as a method for evaluating published patent applications for obviousness. Specifically, Case Study 2 uses EP 1628823 B1 (also published as: CA2526100A1, CN1812878A, CN100553949C, EP1628823A2, EP1628823B8, EP2269808A1, US7569273, US20050003189, WO2004113042A2) developed by Bredt et al. of the Z Corporation as an example. The purpose of this Case Study is to demonstrate how the algorithm could be used to 
Pre-print: Joshua M. Pearce. A novel approach to obviousness: An algorithm for identifying prior art concerning 3-D printing material. World Patent Information 42, 13-18 (2015). doi:10.1016/j.wpi.2015.07.003

prevent both practicing and non-practicing entities from reducing the rate of development of 3-D printing technology. It should be noted that this is merely an example patent with broad claims and no inference should be made concerning motives to slow innovation of either $\mathrm{Z}$ Corporation or their current parent company after acquisition in 2012 by 3-D Systems.

EP 1628823 B1 is titled: "Thermoplastic powder material system for appearance models from 3 -D printing systems" $\left[{ }^{40}\right]$. The patent is fundamentally a materials 3-D printing patent. The algorithm can be used to protect such 3-D printing materials in several ways. First, the USPTO has already expressed interest on the use of crowd-sourcing access to prior art $\left[{ }^{41}\right]$ and the algorithm output can be provided to the USPTO before a patent is granted. Similarly, patent lawyers can make use of the algorithm as demonstrated below during all stages of patent prosecution, opposition and litigation to ensure that obvious 3-D printing materials are not excluded from the public domain.

The first Claim for this patent is: "A powder adapted for three-dimensional printing, the powder comprising: a loose and free-flowing particulate mixture comprising: at least $50 \%$ by weight of a thermoplastic particulate material selected from the group consisting of acetal polyoxymethylene, polylactide". It is interesting to note that the second restricted material is polylactide or polylactic acid (PLA) is well known in the low-cost 3-D printer community. Claim 1 continues with many more materials, "ethylene vinyl acetate, polyphenylene ether, ethylene-acrylic acid copolymer, polyether block amide, polyvinylidene fluoride, polyetherketone, polybutylene terephthalate, polyethylene terephthalate, polycyclohexylenemethylene terephthalate, polyphenylene sulfide, polythalamide, polymethylmethacrylate, polysulfones, polyethersulfones, polyphenylsulfones, polyacrylonitrile, poly(acrulonitrile-butadiene-styrene), polyamides, polystyrene, polyolefin, polyvinyl butyral, polycarbonate, polyvinyl chlorides, ethyl cellulose, cellulose acetate cellulose xanthate, and combinations, and copolymers thereof; and ...". As can be seen from the list of thermoplastics in Claim 1, it is clear that a sub-set of materials covered in Terms 1 and 3, while making claims related to combinations of Terms 4 and 5. It should be noted, that this patent has a publication date of October 26, 2011, filing date of May 19, 2004 and the provisional U.S. application was filed on May 21, 2003. The operative date for determining novelty or obviousness is the filing date of the US provisional priority document if the priority claim is supported. This date is long after many 3-D printers all over the world were using thermoplastics for 3-D printing (see for example commercialized Stratasys systems in 1992).

The primary claim can also be interpreted as being about the size of the particles of plastic, which would clearly be covered under Term 7 . The first Claim continues: "no more than $30 \%$ by weight of an adhesive particulate material either comprising a water-soluble resin including at least one of" and then goes on to list many more materials covered by Terms 1 and 3 and ends the list with "or combinations or copolymers thereof," identical to the Terms 4 and 5 combinations. The adhesive particles act as functional agents (e.g. binders) following Term 6 and again any benefits from their size would be included in Term 7. Finally Claim 1 ends with "whereby the adhesive particulate material is adapted to bond the thermoplastic particulate material when a fluid activates the adhesive particulate material by dissolving the adhesive particulate material the thermoplastic particulate material being substantially inert within the fluid, and wherein the particles of the particulate mixture have a mean diameter of $10 \mu \mathrm{m}$ to $100 \mu \mathrm{m}$." Again the functionality of the fluid follows from Term 6 and the final size-related benefits could be developed by Term 7 . 
Pre-print: Joshua M. Pearce. A novel approach to obviousness: An algorithm for identifying prior art concerning 3-D printing material. World Patent Information 42, 13-18 (2015). doi:10.1016/j.wpi.2015.07.003

Claims 2 through 15 of the Case Study patent cover slightly more detail and expand the range of materials that make up the powder in Claim 1. For example, Claim 2 covers the powder in Claim 1 and all aqueous fluids (Claim 4 handles non-aqueous), and Claim 10 covers the powder where the filler is made of an "organic material". All of these Claims are subsets of the number of $\mathrm{N}$ and $\mathrm{M}$ materials covered in the algorithm. Claim 16 is the method of 3-D printing for using all these materials and Claim 17 is 3-D printed products made from these materials.

It should, be clear to the reader how such an example patent or collection of patents could be used by both practicing and non-practicing entities to limit the technical development of materials for 3-D printing. Case Study 2 shows how the algorithm can be used to obstruct i) broad patent claims (e.g. the list of thermoplastics), ii) vague and generic claims (e.g. organic materials) formulaic patent claims (e.g. covering both aqueous and non-aqueous fluids), and combinatorial claims (e.g. "combinations or copolymers thereof"). This obstruction comes in the form of making obviousness more clear for patent examiners because the idea (or intellectual property) could be easily generated by a simple algorithm.

\section{Discussion}

This concept of obviousness for materials in 3-D printing can be difficult to grasp because of the large selection of natural and man-made materials available in the set of $\mathrm{N}$ and $\mathrm{M}$. To make it more clear, consider a hypothetical constrained world with less material selection - e.g. if the natural (n) and man-made $(\mathrm{m})$ both only consisted of three materials. In this world a design problem might be to make a 3-D printed candy snack and the candy designer would need to choose from: $\mathrm{n}_{1}=$ cocoa, $\mathrm{n}_{2}=$ peanuts, $\mathrm{n}_{3}=$ sugar, $\mathrm{m}_{1}=$ chocolate, $\mathrm{m}_{2}=$ peanut butter, and $\mathrm{m}_{3}=$ cotton candy. Using the algorithm the obvious materials for 3-D printing would include $\mathrm{n}_{1}, \mathrm{n}_{2}, \mathrm{n}_{3}, \mathrm{~m}_{1}, \mathrm{~m}_{2}, \mathrm{~m}_{3}, \mathrm{n}_{1} \mathrm{n}_{2}, \mathrm{n}_{1} \mathrm{~m}_{1}, \mathrm{n}_{1} \mathrm{~m}_{2}$, and so forth. Therefore, following current patent law in this hypothetical material-constrained world, it should not be possible to patent a material for 3-D printing like $\mathrm{m}_{1} \mathrm{~m}_{2} \mathrm{n}_{3}$ (e.g. a chocolate and peanut butter snack coated in sugar, which ironically was just published in 2011 by General Mills for non-3-D printed applications as shown in claim 15 of U.S. patent US20110020502 A1) [ ${ }^{42}$ ]. It should be noted that a notice of appeal has been filed according to the USPTO PAIR database. Making lists of what could be potentially useful 3-D printable materials from a subset of materials (as is done in Case Study 2 above) can be considered obvious and simply selecting from a large pool of $\mathrm{N}$ or $\mathrm{M}$ makes it no less obvious. Similarly, choosing to change the size of $\mathrm{n} 2$ (different sizes of peanut chunks) in a mixture of $\mathrm{m} 1$ and $\mathrm{m} 2$ (chocolate and peanut butter) can also be considered obvious. As is coupling a material with a specific function with another. On the other hand, an argument can be made that the combination of various selected parameters from a large pool of available parameters renders the claimed invention non-obvious if the combination has not been previously proposed or suggested in the prior art. This could explain why such broad patent claims are granted. Such arguments are more difficult to make after an algorithm like the one discussed here has been released as patenting is currently only allowed in the U.S. for non-obvious inventions. Interestingly, patenting the algorithm itself is not currently allowed under patent law as it is considered to be an abstract concept [ ${ }^{43}$.

Determining the importance of intellectual property (IP) monopolies on unhealthy snack choices is beyond the scope of this paper. However, limiting overly broad and innovation-constricting IP claims is important to resolve because of the enormous recent growth in the 3-D printing industry and media attention that has led to a rapid increase in patenting of 3-D printing technology. In 2012, the 
Pre-print: Joshua M. Pearce. A novel approach to obviousness: An algorithm for identifying prior art concerning 3-D printing material. World Patent Information 42, 13-18 (2015). doi:10.1016/j.wpi.2015.07.003

global market for 3-D printing / AM products and services grew at a compound annual growth rate (CAGR) of $28.6 \%$, increasing from US $\$ 1.714$ billion in 2011 to US $\$ 2.204$ billion [44]. This investment has come with a significant increase in the number of 3-D printing and additive manufacturing patents. Where as in 2001 there were under 50 patents, the growth has shot up by a factor of 2 by 2006, and by more than a factor of 10 to over 550 patents in 2013 [ $\left.{ }^{45}\right]$. This acceleration of aggressive patenting in the 3-D printing space is already causing concern for some of the 3-D printing industry members and to the wider technology community. It has even been suggested that aggressive patenting in 3-D printing could be used as a strategic national industrial weapon $\left.{ }^{46}\right]$. To illustrate this concern and to combat innovation-stifling 3-D printing claims, the Electronic Frontier Foundation (EFF) is using crowdsourcing of prior art to support pre-issuance submissions filed in the U.S. Patent Office to defeat pending patent claims relating to 3 -D printing $\left[{ }^{47},{ }^{48},{ }^{49},{ }^{50}\right]$. This EFF approach may prove to be useful, and the algorithm provided here could be used in an effort to identify prior art that could render broad patent claims directed at known and useful 3-D printing materials (e.g. thermoplastics). Although most industry observers are against broad patents, there are still many that believe patents benefit innovation. However, evidence to the contrary is now considerable as there is a growing body of literature that form the view that intellectual property in general and the patent system in particular actually stifles innovation $\left[{ }^{51},{ }^{52},{ }^{53},{ }^{54},{ }^{55},{ }^{56},{ }^{57},{ }^{58},{ }^{59},{ }^{60},{ }^{61}\right]$. For example, Scherer [ $\left.{ }^{62}\right]$ shows there is a direct contradiction with the historical consensus of the social usefulness of patents. Restricting considerations to only the 3-D printing innovation space, the potential of patents to stifle innovation appears clear. When the IP restrictions expired, the RepRap project was born, which enabled an explosion of innovation, growth of small businesses and a concomitant aggressive reduction in 3-D printer costs. These trends are continuing to accelerate in an open-source ecosystem supporting more than one hundred 3-D printing businesses. These businesses have only begun to acquire their full market potential primarily, because they are limited to relatively simple thermoplastic materials with limited properties (e.g. single color ABS printing). The risks of allowing broad 3-D printing material patents is that the full market potential of 3-D printing may be stifled.

There is evidence of this type of "intellectual property tragedy" in other fields that have a direct impact on the future of 3-D printing. For example, in the field of nanotechnology, a "patent thicket" has developed with a large number of overlapping claims on "building block" technologies that prevent innovations from reaching the market $\left[{ }^{63},{ }^{64},{ }^{65},{ }^{66},{ }^{67},{ }^{68}\right]$. Many of these building block technologies are materials (e.g. carbon nanotubes) that are likely to be useful in 3-D printing applications. It is similarly clear that broad patent claims on materials for 3-D printing will hamper the 3-D printing community's ability to innovate and bring better products to the market. The algorithm evaluated in this paper can provide a defensive publication of prior art to help identify obvious materials for 3-D printing in order to limit broad claims of known and obvious material combinations. Following the non-obvious requirement under patent law, patent claims attempting to protect such 3-D printing materials should be denied and the algorithm can assist in identifying such materials. Similarly, existing patents attempting to protect materials that can be identified using this algorithm should be re-evaluated, as they would be obvious to any materials scientist with a basic understanding of 3-D printing (unless making a working combination of the materials required a non-obvious extension of known materials science methods).

Microsoft's Bill Gates perhaps best summarizes the risks to any early industry when discussing software patents that he opposed when the Internet was still young. In 1991, he said: "[i]f people had 
Pre-print: Joshua M. Pearce. A novel approach to obviousness: An algorithm for identifying prior art concerning 3-D printing material. World Patent Information 42, 13-18 (2015). doi:10.1016/j.wpi.2015.07.003

understood how patents would be granted when most of today's ideas were invented and had taken out patents, the industry would be at a complete standstill today...A future start-up with no patents of its own will be forced to pay whatever price the giants choose to impose." [69] Now in a monopoly position, Gates' views have clearly changed $\left[{ }^{70}\right]$, but the fact remains that broad patenting of basic ideas in a field essentially puts a 20 year hiatus on major innovation and technical progress. There are now many methods to enable 3-D printing in the public domain already. In addition, more 3-D printing methods, which are currently restricted by IP, are opening up over the next several years [ $\left.{ }^{71}\right]$. Thus, the greatest potential building block broad patents that could limit innovation in their uses is the coverage of materials for 3-D printing. The results of this study provide a possible shield against such intellectual property limitations of 3-D printing materials and thus, a more open development of 3-D printing materials enabling the 3-D printing industry and community to innovate in materials space without the stifling concerns of intellectual property law.

Chin $\left[{ }^{72}\right]$ has successfully used a similar argument in the law literature, specifically focused on DNA rather than 3-D printing. Chin wrote an algorithm to generate of 11 million "obvious" nucleotide sequences. To have the sequences count as prior art, he actually constructed the program and tabulated the list on a CD-ROM that was made public. This algorithmic approach has already proven effective at anticipating prior art against oligonucleotide composition claims filed since his publication of the list and has been cited by the patent office in a number of patents $\left[{ }^{73}\right]$. Currently, patent law uses the term "prior art" to refer to that which can invalidate a patent claim. To serve as prior art, something must qualify as a "printed publication", which means it needs to be (1) in some tangible, permanent form (e.g. CD-ROM) and (2) publicly available. But following current U.S. patent law publishing the algorithm is not treated the same as if each material combination/permutation being published. Thus under current law the algorithm does not count as prior art, only if a program was run to generate a text document with all of the combinations. This represents a perceived deficiency in the current law as for any working material scientist the algorithm is indistinguishable from a long text document for providing prior art for 3-D printing materials. Again for clarity, consider the case of a material constrained candy world again. Knowing that $\mathrm{n}_{2} \mathrm{~m}_{1}, \mathrm{n}_{3} \mathrm{~m}_{1}, \mathrm{n}_{2} \mathrm{n}_{3}$, are possible combinations is obvious even if the text "chocolate-peanuts", "sugar-chocolate", or " peanut-sugar" are not contained in a text file sitting on a CD-ROM in some library. Similarly, knowledge of the proposed algorithm and a finite list of chemicals with known properties should render any of them or combination of them obvious for the application of 3-D printing or additive manufacturing.

To eliminate novelty in a patent claim, the reference must not only list the product, but also "enable" one to make the product in any case where the method is not obvious to one with ordinary skill in the relevant technical field. Part of the reason that Chin's work was so effective is that his algorithm relied on a well-known method to fabricate his list of nucleotide sequences. This has not been done in this case, but clearly makes the combination of any known materials for 3-D printing applications obvious to anyone even modestly skilled in the field. Thus, this algorithm could be a useful tool to help examiners identify and reject inappropriately broad or obvious patent claims.

Simply because this algorithm can enumerate all combinations of materials does not imply this algorithm can identify which of those combinations have useful properties for 3-D printing or for the resultant 3-D printed objects. In no way is the algorithm meant to devalue the hard work of materials scientists in developing new materials for 3-D printing. Clearly, the methods used to make novel 
Pre-print: Joshua M. Pearce. A novel approach to obviousness: An algorithm for identifying prior art concerning 3-D printing material. World Patent Information 42, 13-18 (2015). doi:10.1016/j.wpi.2015.07.003

materials, even if they are listed by the algorithm may be patentable. In addition, it is possible that patent examiners will believe that the results given from the algorithm presented in this paper are too broad to be considered a shield against obviousness. In legal regions where this occurs, patent law may need to be altered significantly in order to enable the 3-D printing industry in those regions to be internationally competitive. Although the use of personal 3-D printers for persona, non-commercial use will not constitute patent infringement in the UK [74], U.S. patent law allows for no such personal exception. Thus, if a 3-D printed material is patented, no one may use it unless they pay for a license including hobbyist, prosumer and maker-printed objects for personal consumption. These kind of restrictions, if ever broadly enforced, could have far reaching negative consequences for innovation in the 3-D printing space and create a large public backlash, as IP would be seen as a restriction of personal freedom. Worse, such restrictions would slow the scientific renaissance from leveraging major cost reductions from 3-D printing scientific hardware $\left[{ }^{75},{ }^{76}, 77,{ }^{78},{ }^{79}\right]$. Most importantly, it would hamper the application of 3-D printing to provide sustainable development in the developing world by again radically reducing costs of appropriate technologies or access to low-cost medical care $\left[{ }^{80},{ }^{81},{ }^{82}\right]$. Hampering these applications of 3-D printing, among others, would likely create increased tension over IP law. As Hornick has pointed out, the tension between the abilities of 3-D printing and the current law, indicate a major shift in IP law or potentially, even its demise [83].

\section{Conclusions}

The open-source algorithm for identifying prior art concerning 3-D printing materials discussed in this article provides several methods to assist the development and protection of public domain materials for low-cost open-source 3-D printers. In addition, it was shown that by using the algorithm it can help to identify those materials or combinations thereof from a list of potentially useful 3-D printable materials from a subset of materials that may be obvious. The algorithm can also help to show that by changing the size of material or selecting a material based on a known function may also be obvious. As patent protection is currently only allowed in the U.S. for non-obvious inventions, the algorithm's use should severely restrict any overly broad patent using vague, generic, formulaic and combinatorial claims. The result is a more open development of 3-D materials enabling the 3-D printing industry and community to innovate in materials space without the potential stifling concerns of intellectual property law.

\section{Acknowledgments}

The author would like to acknowledge helpful input from commenters on the original algorithm posted as 3-D Printing Materials You Can't Patent on April 23, 2013 http://www.thingiverse.com/thing:73427

\section{References}


Rifkin J. The Zero Marginal Cost Society: The Internet of Things, the Collaborative Commons, and the Eclipse of Capitalism. Palgrave Macmillan. 2014.

2 The Economist. A third industrial revolution: Special report: Manufacturing and innovation, The Economist. 2012.

3 Lipson H, Kurman M. Fabricated: the new world of 3D printing. John Wiley \& Sons, New York, NY, 2013.

4 Jones R, Haufe P, Sells E, et al. Reprap- the replicating rapid prototyper. Robotica 2011;29(1):177-191.

5 Bowyer A. 3D Printing and Humanity's First Imperfect Replicator. 3D Printing and Additive Manufacturing 2014;1(1): 4-5.

6Cano J L C. The Cambrian Explosion of Popular 3D Printing. International Journal of Interactive Multimedia \& Artificial Intelligence 2011;1(4).

7Wittbrodt B T, Glover A, Laureto J, et al. Life-cycle economic analysis of distributed manufacturing with open-source 3D printers. Mechatronics 2013;23(6), 713-726.

8Make, Make:Ultimate Guide to 3D Printing, Make, 2014.

9 Tymrak, B M., Kreiger M, Pearce JM. Mechanical properties of components fabricated with open-source 3-D printers under realistic environmental conditions. Materials \& Design 2014;58, 242-246.

10 Raskin M, Kolet L . Personal 3-D printer sales jump 35,000\% since 2007. Bloomberg; October 24, 2012; http://www.bloomberg.com/news/2012-10-24/personal-3-d-printer-sales-jump-35-000-since-2007.html (accessed 5.1.14)

11 Baechler C, DeVuono M, Pearce JM. Distributed recycling of waste polymer into RepRap feedstock. Rapid Prototyping Journal 2012;19(2), 7-7.

12Kreiger M, Pearce JM. Environmental Life Cycle Analysis of Distributed Three-Dimensional Printing and Conventional Manufacturing of Polymer Products. ACS Sustainable Chemistry \& Engineering 2013;1(12), 1511-1519.

13 Feeley SR, Wijnen B, Pearce JM. Evaluation of Potential Fair Trade Standards for an Ethical 3-D Printing Filament. Journal of Sustainable Development 2014; 7(5), 1-12.

14 Appropedia. RecycleBot. http://www.appropedia.org/Recyclebot (accessed 5.1.14)

15 Lyman, H. Lyman Filament Extruder V4.1, http://www.thingiverse.com/thing:265375 (accessed 5.1.14)

16 D3D Innovations Ltd., Produce filament for your 3D Printer, http://www.filafab.co.uk/ (accessed 5.1.14)

17 Filabot, 3D printer filament, http://www.filabot.com/ (accessed 5.1.14)

18 Elmore T. Filastruder, http://www.filastruder.com/ (accessed 5.1.14)

19 Hunt EJ, Zhang C, Anzalone N, Pearce JM. Polymer recycling codes for distributed manufacturing with 3-D printers, Resources, Conservation and Recycling 2015; 97, 24-30.

20 Altshuller GS. The innovation algorithm: TRIZ, systematic innovation and technical creativity. Technical Innovation Center, Inc. 1999.

21Altshuller G. Principles: TRIZ keys to innovation (Vol. 1). L. Shulyak, \& S. Rodman (Eds.). Technical Innovation Center, Inc. 1998.

22Jian-rong Z, Fan W, Jing D, et al. Study on improving the operating experiments with application of the TRIZ. Mechanical Research \& Application, 2013;1,003.

23Ilevbare IM, Probert D, Phaal R. A review of TRIZ, and its benefits and challenges in practice. Technovation 2013;33(2), 30-37.

24 Heigl, H. New Extruder and Shredder concept - Using methods of innovative engineering (TRIZ), Available: http://www.thingiverse.com/thing:262361 (accessed 5.1.14)

25 CAS REGISTRY, https://www.cas.org/content/chemical-substances (accessed 7.8.15)

26 Simovski CR. Material parameters of metamaterials (a review). Optics and Spectroscopy 2009;107(5), 726-753.

27 Soukoulis C. Photonic Metamaterials: Review, Challenging and Opportunities. In APS March Meeting Abstracts 2013;1, 3003.

28 Poole CP, Owens FJ. Introduction to nanotechnology. Wiley, Hoboken, NJ, 2003.

29 Feilden B. Conservation of historic buildings. Routledge, 2003.

30 Smith JB, Schneider SH, Oppenheimer M, et al. Assessing dangerous climate change through an update of the Intergovernmental Panel on Climate Change (IPCC)“reasons for concern”. Proceedings of the National Academy of Sciences 2009;106(11), 4133-4137.

31 McMichael AJ, Woodruff RE, Hales S, Climate change and human health: present and future risks. The Lancet 2006; 367(9513),859-869. 
32 Stern N. The Economics of Climate Change: The Stern Review, Cambridge University Press: Cambridge, UK, 2007.

33 Intergovernmental Panel on Climate Change. Climate Change 2014: Impacts, Adaptation, and Vulnerability. http://www.ipcc.ch/report/ar5/wg2/ (accessed 5.1.14)

34 Wackernagel M, Rees WE. Our ecological footprint: reducing human impact on the earth, New Society Publishers, 1998.

35 Pearce JM. Photovoltaics—a path to sustainable futures. Futures 2009; 34(7), 663-674.

36 Markvart T. Solar electricity. John Wiley \& Sons, 2nd edition, New York, NY, 2000.

37 Sargent EH. Colloidal quantum dot solar cells. Nature Photonics 2012;6(3), 133-135.

38 Napadensky E. Inkjet 3D printing. In: The Chemistry of InkJet Inks S Magdassi, (Ed). World Scientific, New Jersey, 2010; pp. 255-267.

39Gwamuri J, Güney DO, Pearce JM, Advances in Plasmonic Light Trapping in Thin-Film Solar Photovoltaic Devices. In: Solar Cell Nanotechnology, Wiley, Hoboken, NJ, 2013; 241-269.

40 Bredt JF, Clark SL, Williams DX, et al. "Thermoplastic powder material system for appearance models

from 3d printing systems" Z Corporation, Thermoplastic powder material system for appearance models from 3d

printing systems. Patent EP 1628823 B1 also published as CA2526100A1, CN1812878A, CN100553949C, EP1628823A2, EP1628823B8, EP2269808A1, US7569273, US20050003189, WO2004113042A2, WO2004113042A3.

41 USPTO. USPTO to Host Roundtable on Crowdsourcing Access to Prior Art. March 24, 2014 http://www.uspto.gov/about-us/news-updates/uspto-host-roundtable-crowdsourcing-access-prior-art (7.8.15)

42 Nack TJ, Pollen NR, Geoffrion JW. Chocolate and peanut butter slurry topical coating for snack products. US Patent US 20110020502 A1.

43 Peterson MR. Now You See It, Now You Don't: Was It a Patentable Machine or an Unpatentable Algorithm-On Principle and Expediency in Current Patent Law Doctrines Relating to Computer-Implemented Inventions. Geo. Wash. L. Rev. 1995; 64, 90.

44 Wohlers T. Tracking Global Growth in Industrial-Scale Additive Manufacturing. 3D Printing and Additive Manufacturing. 2014;1(1): 2-3.

45 Gridlogics Technologies Pvt Ltd. 3D Printing Technology Insight Report : An analysis of patenting activity around 3DPrinting from 1990-Current. Gridlogics Technologies Pvt Ltd. 2014.

46 Pearce JM, Haselhuhn, A, Using Intellectual Property as a Stategic National Industrial Weapon:The Case of 3-D Printing.Engineer 2015; 29-31.

47 Hornick J, Bhushan A. Crowdsourcing prior art to defeat 3D printing patent applications. 3D Printing Industry; May 17, 2013; http://3dprintingindustry.com/2013/05/17/crowdsourcing-prior-art-to-defeat-3d-printing-patent-applications/ (accessed 5.1.14)

48 Walsh K. Insider insight —fighting the 3D printing patent applications. 3D Printing Industry; June 3, 2013; http://3dprintingindustry.com/2013/06/03/insider-insight-fighting-the-3d-printing-patent-applications/ (accessed 5.1.14)

49 Honka A. EFF fight for open 3D printing. 3D Printing Industry; March 26, 2013; http://3dprintingindustry.com/2013/03/26/eff-fight-for-open-3d-printing/ (accessed 5.1.14)

50 Park R. Championing 3D printing innovation \& freedom, EFF leads a challenge on six 3D printing patent applications. 3D Printing Industry. http://3dprintingindustry.com/2013/04/17/championing-3d-printing-innovation-freedom-effleads-a-challenge-on-six-3d-printing-patent-applications/ (accessed 5.1.14)

51 Boldrin M, Levine DK. Against intellectual monopoly, Cambridge: Cambridge University Press, 2008.

52 Mowery DC, Nelson RR, Sampat BN, et al. The growth of patenting and licensing by U.S. universities: an assessment of the effects of the Bayh-Dole act of 1980, Research Policy 2001; 30, 99-119.

53 Heller MA, Eisenberg RS. Can Patents Deter Innovation? The Anticommons in Biomedical Research, Science 1998;280, 698-701.

54 Garfinkel SL, Stallman RM, Kapor M. Why patents are bad for software, in P. Ludlow (ed.), High Noon on the Electronic Front: Conceptual Issues in Cyberspace,MIT, Cambridge, 1999; pp. 35-46.

55 Boldrin M, Levine DK. Rent Seeking and Innovation, Journal of Monetary Economics, 2004;51: 127-160.

56 Boldrin M, Levine DK. The economics of ideas and intellectual property, Proceedings of the National Academy of Sciences 2005;102: 1252-56.

57 Boldrin M, Levine DK. The case against intellectual property. American Economic Review, 2002;209-212.

58 Boldrin M, Levine DK. The case against patents. Journal of Economic Perspectives, 2013;27(1), 3-22.

59 Kinsella NS. Against intellectual property. Journal of Libertarian Studies 2001;15(2), 1-54. 
60 Bessen J, Meurer MJ. Patent failure: How judges, bureaucrats, and lawyers put innovators at risk. Princeton University Press, 2008.

61 Lemley MA. Myth of the Sole Inventor, The. Mich. L. Rev. 2011;110, 709.

62 Scherer FM. Political Economy of Patent Policy Reform in the United States. The. J. on Telecomm. \& High Tech. L. 2009; 7, 167.

63 Stiles AR. Hacking Through the Thicket: A Proposed Patent Pooling Solution to the Nanotechnology "Building Block" Patent Thicket. Drexel Law Review 2012;4,555-592.

64 Einsiedel EF, Goldenberg L. Dwarfing the Social? Nanotechnology Lessons from the Biotechnology Front. Bulletin of Science Technology \& Society 2004;24:28:33.

65 Lemley MA, Patenting Nanotechnology. Stanford Law Review 2005;58:601-630.

66 Vaidhyanathan S. Nanotechnologies and the Law of Patents: A Collision Course. In Mehta, M. \& Hunt, G. (Eds.), Nanotechnology: Risk, Ethics and Law. Earthscan, London, 2006; pp.225-236.

67 Pearce JM. Make nanotechnology research open-source. Nature 2012;491, 519-521.

68 Pearce JM. Open-source nanotechnology: Solutions to a modern intellectual property tragedy, Nano Today 2013: 8(4), 339-341.

69 Lee TB. A Patent Lie. The New York Times 2007. http://www.nytimes.com/2007/06/09/opinion/09lee.html (accessed 5.1.14)

70 Brodkin J. Bill Gates still helping known patent trolls obtain more patents. Ars Technica. 2013. http://arstechnica.com/tech-policy/2013/08/bill-gates-still-helping-known-patent-trolls-obtain-more-patents/ (accessed 5.1.14)

71 Hornick J, Rol D. Many 3D Printing Patents Are Expiring Soon: Here’s A Round Up \& Overview of Them. 3D Printing Industry. http://3dprintingindustry.com/2013/12/29/many-3d-printing-patents-expiring-soon-heres-roundoverview/ (accessed 4.29.14).

72 Chin, A. Artful Prior Art and the Quality of DNA Patents. Ala. L. Rev., 57, 975, 2005.

73 Chin, A. Gene Probes are Unpatentable Printed Matter. Fed. Cir. BJ, 20, 527, 2010.

74 Bradshaw S, Bowyer A, Haufe P. The intellectual property implications of low-cost 3D printing. ScriptEd 2010;7(1), 5-31.

75 Pearce JM. Building research equipment with free, open-source hardware. Science 2012;337(6100), 1303-1304.

76 Pearce JM. Open-Source Lab: How to Build Your Own Hardware and Reduce Research Costs. Elsevier. New York 2014.

77 Herrmann KH, Gärtner C, Güllmar D, Krämer M, Reichenbach J R. 3D printing of MRI compatible components: Why every MRI research group should have a low-budget 3D printer. Medical Engineering \& Physics 2014; 36(10), 13731380.

78 Pearce JM. Quantifying the Value of Open Source Hardware Development. Modern Economy 2015; 6, 1-11.

79 Baden T, Chagas AM, Gage G, Marzullo T, Prieto-Godino LL, Euler T. Open Labware: 3-D Printing Your Own Lab Equipment. PLOS Biology 2015; 13(3). DOI: 10.1371/journal.pbio.1002086

80 Pearce JM, Blair CM, Laciak KI, et al. 3-D Printing of Open Source Appropriate Technologies for Self-Directed Sustainable Development. Journal of Sustainable Development 2010;3(4), 17-29.

81 Campbell T, Williams C, Ivanova O, et al. Could 3D Printing Change the World?. Technologies, Potential, and Implications of Additive Manufacturing. Washington, DC: Atlantic Council, 2011.

82 Pearce JM. Applications of Open Source 3-D Printing on Small Farms. Organic Farming 2015; 1(1), 19-35.

83 Hornick JF. 3D Printing and the Future (or Demise) of Intellectual Property. 3D Printing and Additive Manufacturing. 2014;1(1): 34-43. 